\section{The Ritual Use of Jhakro in Magar Community}

\author{
Prakash Prasad Sapkota
}

\section{Abstract}

Human- plant relation is tightly attached on life of human beings. From the beginning of civilization, people used many plants and their products for different purpose to adopt with their environment. The essential and valuable materials including plant species are gathered, used, saved and always remain hunger for knowledge yet now. They developed different kinds of ceremonies and rituals and include valuable materials and plants within it to protect and remains as indigenous knowledge in particular communities and groups. In this context, I wants to raise the issue of material culture to search why people used plants in their rituals with reference to a plant species the Jhakro the Magars inhabitant of Baglung district, western Nepal. The research was carried out by using descriptive and exploratory research design. Observation, interview and group discussion were used in the field for primary data collection. The Magars are rich in their rituals among them death and kul pujane rituals are significant for cohesive and solidarity of the group; within these rituals a shrub plant species with special type of smell remains in central position for purity and soul. They believed that in death ritual all the polluted activities are purified and in kul pujane Jhakro acts as purity as well as help to join their ancestors with them. Unfortunately, they are unknown of the materialistic meaning of it due to lack of transferring knowledge. In etic aspect, this plant has important medicinal properties and the Magar preserved by keeping it in important rituals within their community.

Keywords: Ritual, Jhakro, the Magars, ethno-botany, ancestors

\section{Introduction}

This paper is based on field research, which was carried out in September 2010 to January 2011 within Magar community in Langaouan of Baglung District, western Nepal.

The word community is derived from two Latin words com means together and munis means serving. It means that the group of people living within a limited geographic area, share whole set of interests with we feeling, having complexity of relations as well as feeling more or less same sentiments and attitudes and possesses the basic institutions by means of which a common life is made possible. "A human community is a functionally related aggregate of people who live in a particular geographic locality at a particular time, share a common culture are arranged in a social structure, and exhibit and awareness of their uniqueness and separate identity as a group”(Bhusan et al., 1999).

In each community, they have their own rituals which are continuously going on in their practice. They celebrate different rites and rituals which binds them in their own identity, cohesive nature and solidarity. They celebrate their rituals by different ways. In each system they use different kinds of materials, with giving the importance of different plant species. Rituals activities are transfer to their descendent but the knowledge and importance of such materials is going to be vanished continuously. In this context, this research paper is concerned with the study and searching of the answers, why some plants specie are important and required for rituals which remain in central position in different communities.

Turner opposed Levi-strauss and Durkheim's concept of the social structure. He argued that in passing from structure to structure many rituals passes through communitas- is a fact of everyone's experience. Communitas is almost always thought of or portrayed by actors as a timeless condition, an eternal now, as "a moment in and out of time", or as a state to which the structural view of time is not applicable. Turner's strategy is to approach society not only as social structure it is the combination of social structure and communitas. He further said that preliterate societies, out of the 
need for mere survival, provide little scope for leisure. Thus it is only by ritual flat, acting through the legitimate authority vested in those who operate the ritual cycle that opportunities can be created to put men and women outside their everyday structural potions in family, lineage, clan and chieftainship. In such situations as the liminal periods of major rites de passage the "passengers and crew" are free, under ritual exigency, to complete for a while the mysteries that confront all men, the difficulties that peculiarly best their own society, their personal problems and the ways in which their own wisest predecessors have sought to order, explain, explain away, cloak or mask (cloak-conceal, mask-is to impose the features of a standardized interpretation) these mysteries and difficulties (Turner 1980).

The society has social structure which forms strong and cohesive solidarity between the peoples and communities. The social system is promoted, operated and regulated within the society. People always search and hunger of knowledge. What type of knowledge he gather is old and on the base of it, wants to search new always to go forward continuously from its evolution. Knowledge helps to promote the social structure by increasing cohesive solidarity to adjust within their environment in each community and time. Norms and values are developed in time, space context by the people within their environment and refine continuously. For this they apply everyone's experience and knowledge to operate the community for the better adjustment. In each society, newly born child begins to socialize s/he becomes aware about the norms and values what they could do or not for the survival within their circumstance. S/he learned, practiced and transferred the knowledge for each activities of the member within their communities for better adaptation at that time and context. The norms and values are in practice in the form of rites and rituals in legitimate form in each community. Member of the people in communities practice each their rites and rituals glorified as well as in the name of God and identities. Each rites and rituals of every society have their own meaning from 'etic' and 'emic' perspective; which advance and solidarity to cope with the environment.

\subsection{The Magar}

The Magar is one of the largest ethnic groups of Nepal. Census has reported that the population of the Magar is 1622421, which is 7.14 percentage of the total population of the country (CBS, 2001).The Magars are found mostly in hilly region of Nepal but they are widely spread all over the country. Majority of Magar community is concentrated in western and mid-western hills like Rukum, Rolpa, Baglung, Myagdi, Puthan,Salyan, Mugu, Palpa, Dang on the basis of their population. Nepal living standard survey (2004) states that $34.4 \%$ of the Magars are below the poverty line (Thapa Magar 2010).

The Magars are simple having co-operative nature. The people having normal height, Mangolian face with wheat-white complexion. The face of Chiple Magar is flat and purple wheatwhite in color but Salami and Serwai has slightly elongated face, which may be indicate the inter-breeding between the Magar and other clan (Sapkota,2008).

There are no written documents that could provide factual information about the origin of Magar (Buda Magar, 2061). According to oral history they are the indigenous inhabitants of Magaranth. Magaranth covers large area ranging from the watersheds of Gandaki River to the west up to Karnali River. Magaranth was divided into two regional groups known as 12 Magaranth and 18 Magaranth (Magar and Roka, 2003). Respondents Dil Bahadur Thapa Magar argued that their ancestors were migrated from Humla and settle down in Longaoun of Baglung District. In the question of migration from Palpa District, they surprised with word and said we hearing from you, we don't know. They commonly refused it and explain that our ancestors help to bring statue of Devi from Palpa to Baglung in turn. At that time, the people who take Khadga and walk ahead the statue are now called Khadka of Baglung bazaar. From this time Khadka perform the role of priest in Bhagabati temple of Baglung district. They respect us and since, at the time for worship Devi by Pancha bali (he-goat, he-buffalo, a couple of chicken or pigeon) we paid a minimum charge i. e. five paisa and one mana (half kilogram) rice. Priest returned all parts of sacrifices animals before the contract 
rule established in Bhagabati temple. On the basis of material culture that is Plow R. B. Thapa Magar of seventy years old said-

I left here many years ago and settle in Mahakali Zone of Nepal.My other family members' i. e brothers and other relatives are living here. Once a day when I was engaged to prepare a plow for the plowing of land in my home Mahakali, a neighbor friend came in my house and watched the structure of plow and said that you are Humli ? He added that he had visited Humla and watched the similar structure's of plow used by Humli people for the plowing of land.

Magars have their own language known as Magarkura, but less than half of them can speak it. Magars in some parts of western Nepal also speak the Kham, Kaike and Dhut as their mother language (Thapa Magar, 2010). In the study area all the Magars speak Nepali language and are unable to speak their own language.

In each community, some plant species are used in their rituals activities according to believes norms and values. In Brahmin community, in death rituals Viringiraj a small herbaceous plant is necessary to complete their polluted ritual. In 'emic' prospective, they believed that this plant joined pretatama (soul) to their ancestors. In Magar communities they used 22 kinds of different plant species for their rituals and ceremonies like as Kharsu(Quercus semicarpifolia) used in bartabanda and birth rites and Baans(Bambus spp.),Jhakro, Shreekhanda, Lalupate are used in death rituals. They believe that these plant species purified the polluted situation and save from the evil eyes (Sapkota,2008).

The Magars celebrate different rituals and ceremonies which make them unified, cohesive within the society. It also acts as the demonstrating social, political and cultural resistance. Within many rituals the word Jhakro plays central role in Magar community especially among the Chiple and Salami Magar of the study area. It is noted that "any formal action which is set apart from profanes action and which expresses sacred and religious meaning", the Jhakro has its own meaning in set formal action as death and kulpuja ritual for purity and soul within the Magar community.

\subsection{The Jhakro}

Jhakro is a name of a plant species. In the study area, there is a single plant of this species. It remains in the forest half an hour far on walking distance from the village. Whether it is cultivated by their ancestor or germinated itself, they donot know. It lies in difficult steep rock where people are unable to visit easily. When I observed the plant following with a respondent morphologically, the plant species is perennial shrub. The roots are tap and branched. The stem is erect, branched, solid and creamy in color. The leaves are arranged in whorl on the stem like as node. From this node small branches are developed. The leaves are petiolate, simple, whorl as well as alternate, entire, acute, exstipulate with unicostate reticulate venation. The leaves are shiny, thick with special type of smell. It is difficult to describe this species botanically because Magar cut the main stem of this plant with branches at the time of their rituals, so the plant has not any flowers and fruits.

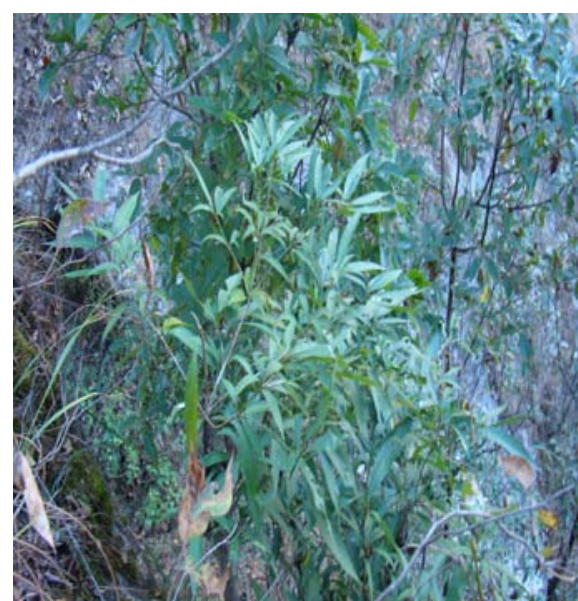

Figure 1: Jhakro plant in natural environment.

\section{Rituals and Jhakro}

Life-cycle rituals continue to have significance in both simple and complex societies. In each society ritual action has their own 
meanings which are culturally transmitted through custom and tradition. Ritual action is seen in all areas of social life and is one of the key means. The individual and groups solve their problems in both the sacred and profane aspects of social existence. Customs and traditions remain alive from generation to generation with the cohesive attachment with their religion. In light of religion Durkheim argued that, religions are collective representations which express collective realities; the rites are a manner of acting which take rise in the midst of the assembled groups and which are destined to excite, maintain or recreate certain mental states in these groups. So if the categories are of religious origin, they ought to participate in this nature common to all religious facts, they too should be social affairs and the product of collective thought(Durkheim,1950 copy in High Points of Anthropology,1980). In Magar society purity and profane of soul are deeply connected with the Jhakro at the time of death. In the life-cycle ritual, death is one of the most important unpleasant, painful and distressing rituals within the Magar community. When a member of the family dies, the other members of the family are to lament with tear. The neighboring members of the village assemble and the older member consoles them. The other member prepared death bed of green bamboo. The dead body is kept on the death bed and covered by shroud (a white thin cloth called kora) and yellow-red thick cloth called the pat. They think pat is a special and pure cloth use to remove pollution. Most favored food of dead people when he was alive, wine, kapur, shrikhanda, rice, flower etc. are put on the mouth of dead body and is taken to Kaligandaki river with spreading la (the mixture of fried rice, abir, coins and flowers) on the cross road. All the mourners offer jal (river water) in the mouth of dead body at last to pay homage to dead soul. Then, finally dagbatti (firing on mouth) is given by elder son and buried on the bank of the river and return to home. Next day, son engage in polluted activities called kiriya garne, at that time, they prepare small hut of tite pati (Artemisia valgaris) and vorlako leaf. Son and his wife and others who are participate in dead pollution remains untouchable, who eat rice without salt and worship their ancestors. They believe that the purity of Jhakro helps to reach soul in their heaven.
The dead pollution is completed on eleventh day. On eleventh day early morning at three, son baths on the tap or well and prepare 22 pinda (rounded stricture of rice and ghee) and keeps on the small branches of Jhakro near the ladder of Jhakro itself, symbol of soul and believes that the ladder help to join death body soul to their ancestors. The ladder, pinda are worships and he prays according to the advice of their priest-bhanja. Then again bathing activities occurs by son and becomes purified. All the polluted materials are buried by bhanja (sister's son) and spread the mixture of cow urine, ghee, milk with dubo (Cynodon dactylon L.) for purifying of the family member as well as the house. The son receives tika from their bhanja and gives tika to his respective sisters, daughters and other relatives by arranging party including local wine. On the day the polluted ritual is over.

\subsection{Kul pujane}

In Magar community, Kul pujne (remembrance of their ancestors) is another important ritual. According to respondents, their ancestral god must be Chandi Baraha because He accepts pig scarifice. There is not clear cut demarcation of the years for Kul puja. In the study area, there is variation in the years of Kul puja between the Magar clans. Generally, they arrange Kul puja at the alternate of seven years. They arrange this ritual at the last of December or January's bright half of a lunar month on Wednesday or Friday. The small branch of Jhakro is kept on the tap on bath in the morning on that day. The house is purified and smeared by the oil of sesame's seeds.

The already prepared pure Jaman (unpurified local wine-jad), pure rice and ginger are eaten in the late morning. In the mid noon at twelve o'clock, all the members are gathered in the place of $k u l$ puja. There is not any temple or fixed place for kul puja. The clans are assemblage in an area and elder member fix the place in every ritual time. The older and knowledgeable members of Magar prepare a hut of titepati. The side of the hut is covered by the broad leaves of bhorlo. The hut has two steps, upper and lower. The ladder of Jhakro kept against the hut to join two steeps. Hens or cocks are also hung oppositely near the ladder. In the corner of the hut, hung a chindo (a dry cover of the gourd used as pot). Inside 
the chindo pot they put barley and sesamum's seeds. Near the ladder, the effigy of kul debata is prepared by the mixture of rice, barley, sesames seeds, ghee etc. When the hens shake their feathers clearly, the people of Magars feel that the god is happy and accepted the gift, then after he starts the puja. The old and knowledgable member of the Magar worship their kul debata (ancestral god) with acheta, pati, cooked rice, pure wine and flowers. At the end of worship, alive heart of black pigs is offered by priest to the god. The ritual rule is that, if pig is female, the chicken must be male or vice-versa. From each family at least a chicken and a black pig must be sacrificed in that ritual. At the nearly end of worship, the priest or other older people catch the branch of Jhakro and tremble with speaking their past, present as well as occurring future events of their family members. This situation is more terrible for all the members of the family because they believe that god is speaking, who has occult powers. After the end of worship, the priest put tika to all the members. According to their respected level within their clan, they divide the different parts of the main sacrifices pig and chickens. Then they went to their home. They eat meat, rice, wine and celebrate happiness to all the members.

\subsection{Cultural importance of Jhakro}

Man is highly developed living beings than other organisms due to capacity of building culture and to adopt easily according to their environment. According to Tylor, culture is that complex whole, which includes knowledge, belief, art, morals, law, custom and any other capabilities acquired by man as a member of society. The people acquired those culture which helps to adopt them easily. In Magar community, they acquired the importance of Jhakro from their ancestors. The two above described ritual's activities are rounds around the plant species Jhakro. They believe that, it is a such type of plant which make purity of their polluted situation of life. They thought that, Jhakro helps to join their ancestors with them.

Death and Kulpija rituals make the Magar community cohesive as well as solidarity. The rules of purity help for the good health of the members. The essential of black pig and chicken sacrifices in different rituals indicate the necessities of the development of animal husbandry and supplement of meet for nutrition. The Jhakro has many medicinal properties and remains in the central place of death and kul puja rituals of the Magar.

\subsection{Symbiotic association between culture and Jhakro}

To begin with, each society must cope with the problem of production-behaviorally satisfying minimal requirements for subsistence; hence there must be an etic behavioral mode of production. The technology and the practice of expanding or limiting the modes of reproduction. The mode of production and reproduction forms the structure. At that time behavioral superstructure is formed. Mental and 'emic' superstructure, meaning the conscious and unconscious cognitive goals, categories, rules, plans, values, philosophies and beliefs about behavior elicited from the participants (Harris,1980).

Marvin Harris is more interested in deciphering the development of specific cultural traits within one society through the use of an etic as well as 'emic' approach and the application of cultural materialism. He argues that we should give materialist's reasons for the phenomenon. As mention Harris, Jhakro should have own special meaning in Magar community and the ancestors of Magar introduced it in central value within most important rituals- death and kulpujane. Unfortunately, the important indigenous knowledge of this plant is not known by the Magars of the study area now. Though, the importance of this plant species has been vanishing among them but practice in their culture is continuously going on.

The cultural traits such as death and kul pujane rituals in Magar community show the symbiotic relations with the plant Jhakro. Though, the Jhakro remains in a single plant in the study area. It is protected due to cultivate or self germinated in difficult steep rocky area in the forest where normally people are unable to destroy it.

On the other hand it is only used in ritual purpose now a day. The Jhakro plant helps to save the cultural rituals of Magars, and their belief and values within the societies. It seems that cultural values 
and the Jhakro are remains as two sides of same coin within the Magar communities.

\section{Conclusion}

In any society of the world, cultural traits are developed by the human beings for their better adaptation within their environment. Environment is changeable. Within this situation human should adjust in changing ecosystem in their society. Food, shelter, cloth and good health are essential to adjust there. For good health people search different plant species, their character and importance. The most of the medically important plant species are saved when they are interlinked with their important cultural traits. In Magar community, the Jhakro and cultural traits death and kulpujne rituals are tightly connected. It makes the Magar community cohesive, solidarity and share we feeling. Symbiotic association between culture and Jhakro is found in Magar community but as Marvin Harris argues, there is materialistic meaning of each cultural trait, but it is vanish within the Magar of the study area about the Jhakro. They only express that Jhakro is pure and essential plant species which is necessary to make happy for our ancestral god as well as to save our dead soul and complete the polluted rituals. In the analysis of 'etic' prospective, the plant Jhakro is one of the most important medicinal plants. It has special smell which can be used as pesticide and other medicinal propose locally, though chemical analysis has not been carried out till now. In the name of modernization, most of the people ignore their cultural values and materials and increase dependency on allopathic medicine day by day. Increasing dependency will not save communities in terrible change in ecosystem of any corner of the world.

\section{Acknowledgments}

I would like to thank the Magar community of Langaoun and especially for Dil Bahadur Thapa Magar, Tirtha Bahadur Thapa Magar, Manrupa Thapa Magar and Prem Bahadur Thapa Magar for their kind co-operation as well as active support in the field. I would like to express my heartfelt thanks to my wife Shanti Sapkota for her assistace during the field work.

\section{References}

Bennett J.W., (1976). The Ecological Transition, Cultural Anthropology and Human Adaptation. New York: Pergamon Press Inc.

Bhusan V.and Sachdeva D.R., (1999). An Introduction to Sociology. A llahabad: Kitab Mahal.

CBS, (2002). Population of Nepal. Village Development Committee/Municipalities. On cast/Ethnicity, Mother Tongue and Religion. HMG Nepal.

Durkheim E., (1915). Elementary Forms of the Religious life. The High Points in Anthropology. Second ed. New York: Alfred A. Knopf

Harris M., (1980). Cultural Materialism: The Struggle for a Science of Culture. New York : Random House, Inc., USA.

Harris M., (1980). Theoretical Principles of Cultural Materialism. The High Points in Anthropology. Second ed. New York: Alfred A. Knopf

Thapa Magar S., (2010).Causes and Impact of Conflict: A Study in the Case of Magars in Western Nepal. Anthropology and Sociology of Nepal. Taking Stock of Teaching, Research and Practice. Central Department of Sociology/Anthropology, Tribhuvan University, Kirtipur, Kathmandu.

Sapkota P.P., (2008). Ethno-Botany: An Anthropological Observation of Magar of Baglung Municipality-9 Langaun. Prayga Sarathi. T.U. Teachers Association Unit Committee M.M.C. Baglung.

Pyakuryal et.al, (2008). Social Science in Multicultural world. Proceedings of the International Conference. Sociology/Anthropology Society of Nepal.

Tyler S.A., (1969). Cognitive Anthropology. Chicago: Holt, Rinehart Turner V.W., (1980). Passage, Margins, and Poverty: Religious Symbols of Communitas. The High Points in Anthropology. Second ed. New York: Alfred A. Knopf. 